\title{
Nanocrystal LEDs with enhanced external quantum efficiency enabled by the use of phosphorescent molecules
}

\author{
Evren Mutlugun**1,2, Agus Putu Abiyasa**1, Burak Guzelturk*², Yuan Gao ${ }^{1}$, Kheng Swee Leck ${ }^{1}$, Xiao Wei \\ Sun ${ }^{1}$, and Hilmi Volkan Demir ${ }^{1,2}$ \\ ${ }^{1}$ LUMINOUS! Centre of Excellence for Semiconductor Lighting and Displays, School of Electrical and Electronic Engineering, School of \\ Mathematical and Physical Sciences, Nanyang Technological University, Nanyang Avenue, Singapore 639798, Singapore \\ ${ }^{2}$ Department of Electrical and Electronics Engineering, Department of Physics, and UNAM - Institute of Materials Science and \\ Nanotechnology,Bilkent University, Ankara, Turkey TR-06800 \\ *These authors contributed equally to this work \\ Email:volkan@bilkent.edu.tr and hvdemir@ntu.edu.sg
}

Abstract: We report efficiency enhancement in quantum dot (QD) based LEDs with the aid of excitonic energy transfer from co-doped TCTA:Ir(ppy) ${ }_{3}$ layer to CdSe/ZnS QDs while providing spectrally pure emission.

\section{Introduction}

Nanocrystal quantum dots (QDs) have attracted significant interest in recent years because of their favorable characteristic features. Tunable optical properties achievable by engineering their particle size and composition make these QDs attractive for use in light-emitting devices. Thus far, there have been numerous reports on the use of QDs in electroluminescent devices including organic light-emitting diodes (LEDs) ${ }^{1-2}$. However, QDs suffer from poor charge injection when used in conventional polymer LED structures. This significantly limits the quantum efficiency of such QD-based devices. On the other hand, phosphorescent materials perform well in LEDs in terms of quantum efficiencies, with reported values of $>20 \%{ }^{3}$. These significant levels of efficiency stem from harvesting the triplet state excitons in phosphorescence LEDs, which is forbidden in fluorescent polymer based counterparts. Yet, the phosphorescent devices also suffer from the spectral purity and limited spectral tunability. Therefore, transferring the triplet state excitons of the phosphorescent molecules to the QDs is a novel approach to achieve spectrally tunable pure emission with possibly high levels of quantum efficiencies in organic LED platforms. Here we report QD based LEDs with the capability of excitonic energy transfer from the co-doped TCTA:Ir(ppy $)_{3}$ to $\mathrm{CdSe} / \mathrm{ZnS}$ QDs while providing spectrally pure emission from the QDs.

\section{Experimental results}

In this work, we employed red-emitting $\mathrm{CdSe} / \mathrm{ZnS}$ QDs as energy accepting agents from the co-doped layer of 2,2',2"-tris-(N-carbazolyl)-triphenylamine: Iridium, tris(2-phenylpyidine) (TCTA:Ir(ppy) 3 ). The synthesis of the quantum dots was performed using a previous recipe reported in the literature ${ }^{4}$ and the as-synthesized quantum dots were highly monodisperse with $<30 \mathrm{~nm}$ full-width at half-maximum and exhibited $>20 \%$ quantum efficiency in the solid film. The device architecture is given in Fig. 1, showing the energy alignments sandwiching hole and electron injection layers. During fabrication, the hole transport layers of polyethylene dioxythiophene:polystyrene sulfonate (PEDOT:PSS) and poly[ $N, N^{\prime}$-bis(4-butylphenyl)- $N$, $N^{\prime}$ bis(phenyl)benzidine] (Poly-TPD) were spin-coated on a pre-cleaned ITO glass, followed by the spin-casting of the QD layer. The device fabrication was then continued by organic evaporation of the successive layers, finally completed with the thermal evaporation of $\mathrm{LiF}$ and $\mathrm{Al}$.

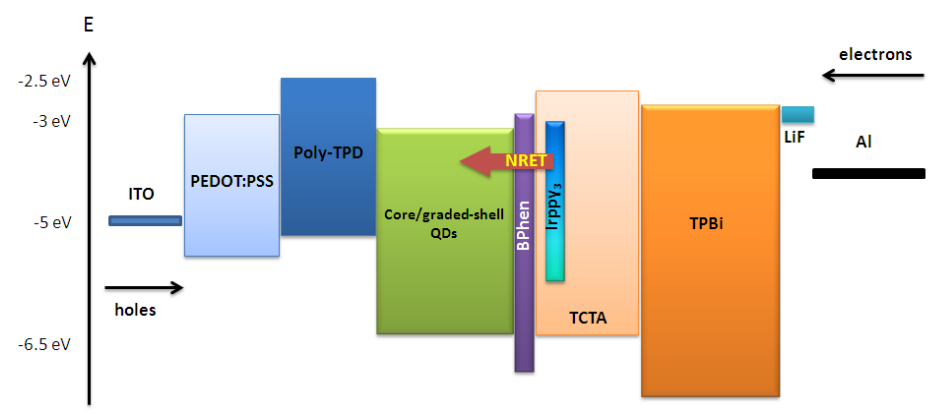

Fig.1. Band alignment for ITO/PEDOT/p-TPD/QD/Bphen/TCTA:Ir(ppy)/3PBI/LiF/Al LED.

Here, we first worked on the optimization of charge balance within the QD-LED structures. We observed that the exciton formation zone can be controlled by using Bathophenanthroline (BPhen) and TCTA together. To investigate the distance dependence of the energy transfer from the green-emitting $\operatorname{Ir}(\text { ppy })_{3}$ layer to the red- 
emitting QDs, we carefully varied the distance of the phosphorescent layer to the QDs. Fig. 2 shows the change in the resulting electroluminescence spectra as we modified the separation between the co-doped layer of $\operatorname{Ir}(\text { ppy })_{3}$ :TCTA and the QDs. As we moved the position of the phosphorescent layer further away from the QD layer with thickening BPhen layer, we observed the increasing electroluminescence coming from $\operatorname{the} \operatorname{Ir}(\mathrm{ppy})_{3}$, which undesirably reduces the color purity, demonstrating the diminishing effect of nonradiative energy transfer. Therefore, while helping with balancing the charge injection, BPhen should not be thicker than needed to maintain the energy transfer. As a result, the BPhen thickness was found to be optimized at a thickness of 1.5 $\mathrm{nm}$, while still allowing for the nonradiative energy transfer from the co-doped $\operatorname{Ir}(\mathrm{ppy})_{3}$ to QDs.

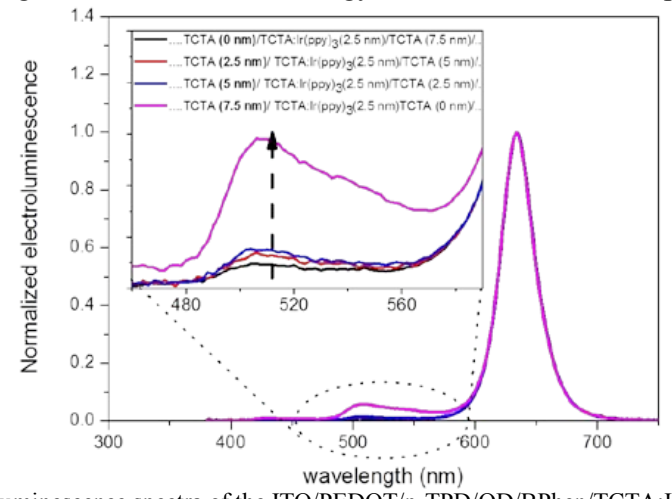

Fig.2. Normalized electroluminescence spectra of the ITO/PEDOT/p-TPD/QD/BPhen/TCTA:Ir(ppy) $3 / \mathrm{TPBI} / \mathrm{LiF} / \mathrm{Al}$ device with varying the position of the co-doped TCTA:Ir(ppy) ${ }_{3}$ layer within the $10 \mathrm{~nm}$ TCTA thickness.

Next we focused on the utilization of phosphorescent molecules within the optimal device architecture to achieve high efficiency along with the color purity. As shown in Fig. 3a, we achieved external quantum efficiency (EQE) greater than $2.1 \%$ using the co-doped $\operatorname{Ir}(\mathrm{ppy})_{3}$ layers $(10 \%$ in TCTA) in close proximity of QDs, whereas the devices without $\operatorname{Ir}(\mathrm{ppy})_{3}$ phosphorescent layer exhibited EQE of only $1.8 \%$ (Fig. 3b).

a)

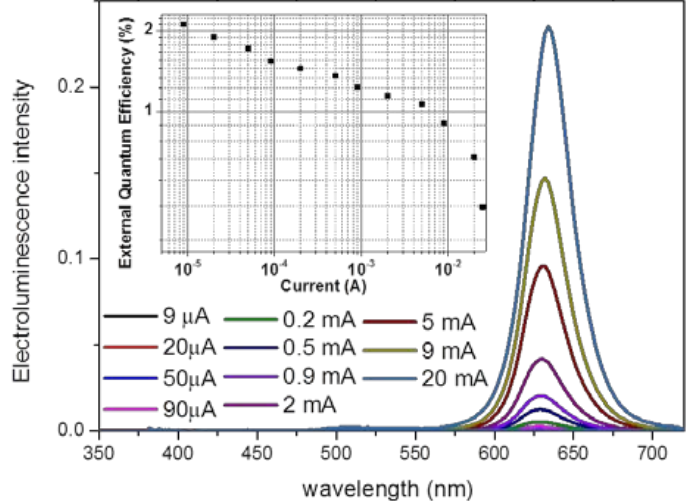

b)

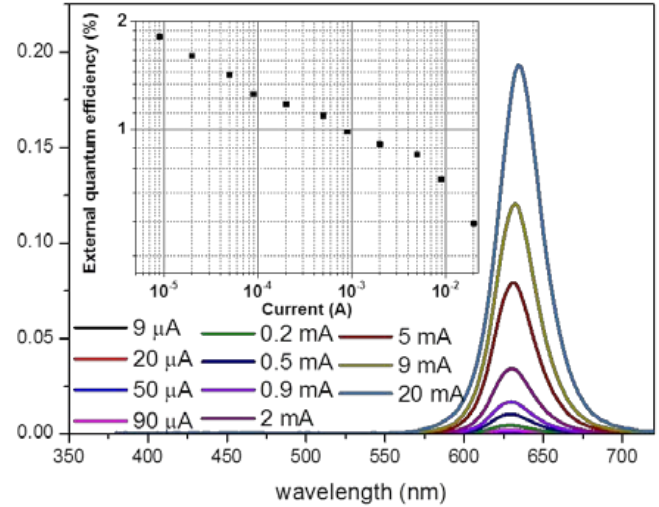

Fig.3. Electroluminescence spectra of (a) ITO/PEDOT/p-TPD/QD/BPhen/ TCTA:Ir(ppy) 3 /TPBI/LiF/Al LED and

(b) ITO/PEDOT/p-TPD/QD/BPhen/TCTA/TPBI/LiF/Al LED, together with their external quantum efficiencies (insets).

\section{Conclusion}

In conclusion, we successfully implemented LEDs utilizing excitonic energy transfer from the co-doped TCTA:Ir(ppy) ${ }_{3}$ to CdSe/ZnS QDs while providing spectrally pure emission and demonstrated enhanced external quantum efficiency in the optimized structure. This work potentially opens up new possibilities for unprecented levels of high efficiencies in QD LED structures with further optimization of the hole injection to the QD layers.

This work is supported by the National Research Foundation of Singapore under Grant No. NRF-CRP-6-2010-2 and NRF-RF-2009-09 and the Singapore Agency for Science, Technology and Research (A*STAR) SERC under Grant No. 112120 2009. HVD also acknowledges EURYI and TUBA.

\section{References}

${ }^{1}$ V. L. Colvin, M. C. Schlamp, A. P. Alivisatos, Nature, 1994, 370, 354.

${ }^{2}$ L. Qian, Y. Zheng, J. Xue, P. H. Holloway, Nature Photon. 2011, 5, 543.

${ }^{3}$ S. W. Liu, Y. Divayana, A.P. Abiyasa, S. T. Tan, H. V. Demir, and X. W. Sun, App. Phys. Lett., 2012, 101, 093301.

${ }^{4}$ W. K. Bae, J. Kwak, J. Lim, D. Lee, M. K. Nam, K. Char, C. Lee, S. Lee, Nano Lett. 2010, 10, 2368. 